\title{
Should We Enhance or Restrict Technological Diffusion from Major to Minor Firms?
}

\author{
Hideki Nakamura ${ }^{1}$, Takeshi Ikeda ${ }^{2}$ \\ ${ }^{1}$ Faculty of Economics, Osaka City University, Osaka, Japan \\ ${ }^{2}$ Faculty of Economics, Daito Bunka University, Tokyo, Japan \\ Email: ^hnakamur@econ.osaka-cu.ac.jp
}

How to cite this paper: Nakamura, $H$. and Ikeda, T. (2018) Should We Enhance or Restrict Technological Diffusion from Major to Minor Firms? Theoretical Economics Letters, 8, 2233-2250. https://doi.org/10.4236/tel.2018.811146

Received: May 11, 2018

Accepted: August 10, 2018

Published: August 13, 2018

Copyright (c) 2018 by authors and Scientific Research Publishing Inc. This work is licensed under the Creative Commons Attribution International License (CC BY 4.0).

http://creativecommons.org/licenses/by/4.0/

\begin{abstract}
This study examines how technological diffusion from a major firm to a minor firm affects social welfare via $\mathrm{R} \& \mathrm{D}$ competition in an asymmetric Cournot duopoly. We assume that the minor firm can decrease its production cost because of the spillover effect arising through $\mathrm{R} \& \mathrm{D}$ by the major firm. $\mathrm{R}$ $\& \mathrm{D}$ by the minor firm depends on the free-riding effect and a taking-away effect that removes market share from the major firm. If given a low $\mathrm{R} \& \mathrm{D}$ cost, both firms invest in $\mathrm{R} \& \mathrm{D}$ with an appropriate level of technological diffusion, we can obtain a high level of social welfare. However, an increase in the level of technological diffusion could make the major firm abandon $\mathrm{R} \&$ D activity. Given a high R \& D cost, a high level of welfare can be obtained only with a low level of technological diffusion because the potential presence of technological diffusion easily disrupts R \& D by the major firm.
\end{abstract}

\section{Keywords}

Asymmetric Cournot Duopoly, R \& D Competition, Technological Diffusion, Free-Riding and Taking-Away Effects

\section{Introduction}

Multinational firms in developed economies extend their businesses to newly industrializing economies to secure new markets and lower wage costs. Some multinational firms in the automobile, computing electronics, information and technology, and pharmaceutical industries have large amounts of R \& D expenses. At the same time, domestic firms in newly industrializing economies can benefit from technological diffusion (see, for example, [1] [2] [3]) ${ }^{1}$. For example,

${ }^{1}$ Those domestic firms can obtain the knowledge about the new techniques for production, developed by the multinational firms. 
in China, domestic firms in the home electronics industry have succeeded in catching up with their multinational counterparts, partly because of technological diffusion (see [4] [5] [6]). Chinese domestic firms have obtained large market shares with the lost by some Japanese firms. Compared with the home electronics industry, in the automobile industry, R \& D expense is high because of the difficulty of assembly. The Chinese government obliges multinational firms to pursue joint ventures with domestic firms that can promote technological diffusion $^{2}$.

It would be worthy to examine the level of technological diffusion from multinational firms to domestic firms on economic efficiency of domestic economies. Hence, this study investigates how the level of technological diffusion affects social welfare with $\mathrm{R} \& \mathrm{D}$ activity. We assume the potential existence of technological diffusion in an asymmetric Cournot duopoly with $\mathrm{R} \& \mathrm{D}$ competition. The unit production cost of the minor firm exceeds that of the major firm, but that both firms can decrease their production costs through $\mathrm{R} \& \mathrm{D}$ activity. The R \& D of the major firm can result in technological diffusion from the major firm to the minor firm. The minor firm can decrease its production cost because technological diffusion can cause the spillover effect arising through the R \& D of the major firm, even though it has no R \& D of its own. Hence, as long as the major firm undertakes R \& D activity, the minor firm can enjoy a free-riding effect and consumers can then benefit from the fall in production costs. Unless the production of the minor firm is significantly inefficient, an increase in the level of technological diffusion can then increase social welfare because the increase in the profit of the minor firm and consumer surplus can exceed the decrease in the profit of the major firm.

Competition in $\mathrm{R} \& \mathrm{D}$ depends on the cost of $\mathrm{R} \& \mathrm{D}$, the production costs of major and minor firms, and the level of technological diffusion. We examine the minor firm's R \& D by considering not only the free-riding effect, but also a taking-away effect in which $\mathrm{R} \& \mathrm{D}$ by the minor firm can remove market share from the major firm. If the $\mathrm{R} \& \mathrm{D}$ cost is low and the level of technological diffusion is also low, the major firm but not the minor firm, invests in $\mathrm{R} \& \mathrm{D}$ because for the minor firm, the free-riding effect outweighs the taking-away effect. Next, given a moderate level of technological diffusion, both the firms invest in R \& D given the coexistence of the free-riding and taking-away effects. Thus, both firms can invest in R \& D and welfare will be very high. Finally, given a high level of technological diffusion, the minor firm but not the major firm, invests in R \& D because the taking-away effect outweighs the free-riding effect. Social welfare can then increase with a rise in the level of technological diffusion as long as the major firm invests in $\mathrm{R} \& \mathrm{D}$ because the minor firm and consumers can benefit from the subsequent technological diffusion. If the $\mathrm{R} \& \mathrm{D}$ cost is high, a high level of welfare can be attained only with a low level of technological diffusion, because an increase in the level of technological diffusion can easily disrupt R \& ${ }^{2}$ Its foreign investment restriction will be totally abolished in 2022 . 
D by the major firm ${ }^{3}$.

To begin, we posit the following. [7] considered an asymmetric Cournot duopoly with R \& D competition and examined social welfare that depended on catch-up by the minor firm and the R \& D activity by the major firm ${ }^{4}$. We extend the analysis of [7] to examine the effect of technological diffusion on social welfare. In our model, the effect of technological diffusion on social welfare differs, depending not only on the cost of R \& D, but also the level of technological diffusion. Given a low $\mathrm{R} \& \mathrm{D}$ cost, the equilibrium depends on the free-riding and taking-away effects of the minor firm. A moderate level of technological diffusion can then increase welfare because it enhances $R$ \& D activities, not only by the major firm, but also by the minor firm. However, if the level of technological diffusion is high, the major firm will abandon $\mathrm{R} \& \mathrm{D}$ activity and this can significantly decrease welfare.

Although we do not consider patents in this paper, we can explore how we can attain a high level of social welfare via technological diffusion ${ }^{5}$. If the cost of R \& $\mathrm{D}$ is low, a high level of welfare can be attained with a moderate level of technological diffusion, that is, with neither an excessively high nor an excessively low level of technological diffusion. If the R \& D cost is high, the level of technological diffusion should be sufficiently low to not disrupt R \& D by the major firm. Hence, our result would be consistent with some studies including [11] [12].

The remainder of the paper is organized as follows. Section 2 describes our model, and Section 3 examines an asymmetric Cournot duopoly with R \& D competition and the effect of technological diffusion on social welfare. We conclude in Section 4 with some policy implications.

\section{Model}

We consider R \& D competition in a linear Cournot duopoly where the firm cost structures are asymmetric. We consider major and minor firms in which the unit production cost of the minor firm exceeds that of the major firm. Both the major and minor firms can decrease their own production costs using their own $\mathrm{R} \& \mathrm{D}$ activity. We assume that the minor firm can decrease its production cost because of the spillover effect arising through the $\mathrm{R} \& \mathrm{D}$ of the major firm.

We consider the following two-stage game with complete information. In stage one, the duopolists simultaneously and irreversibly choose whether to invest in R \& D, represented as yes $(R)$ or no $(N)$. In our model, firms 1 and 2 are the major and minor firms, respectively. By investing in R \& D, firm 1 has a unit cost of $c_{1 R}$ for a sunk cost of $F$. If firm 1 does not undertake $\mathrm{R} \& \mathrm{D}$, its unit ${ }^{3}$ Even when a major firm is a multinational firm, social welfare can include the profit of the major firm because of the taxes on its profit. Additionally, the main conclusion could remain intact with social welfare comprising only consumer surplus and the profit of the minor firm.

${ }^{4}$ If there is a large gap in production costs between the major and minor firms, catch-up by the minor firm may not increase social welfare because of an increase in the inefficient production of the minor firm. This implies the so-called the effect of [8].

${ }^{5}$ See, for example, [9] [10] that explored optimal patent length and breadth and patent licensing. 
cost remains $c_{1 N}\left(c_{1 R}<c_{1 N}\right)$. When firm 1 does not undertake $\mathrm{R} \& \mathrm{D}$, the production cost of the minor firm depends on only $\mathrm{R} \& \mathrm{D}$ of its own. By investing in $\mathrm{R} \& \mathrm{D}$, firm 2 has a unit production cost of $c_{2 R}$ for a sunk cost of $F$ $\left(c_{2 R}<c_{2 N}\right)$ in which $C_{2 N}$ represents a unit production cost with no R \& D of its own. For simplicity, we consider the same $\mathrm{R} \& \mathrm{D}$ cost for the major and minor firms. We assume that $c_{1 N}<c_{2 R}$.

When firm 1 invests in $\mathrm{R} \& \mathrm{D}$, firm 2 can decrease its unit production cost because of technological diffusion. The cost of the minor firm is represented by $\delta c_{2 j} \quad(j=R, N)$ with the assumption that $0<\delta \leq 1{ }^{6}$. Thus, the level of technological diffusion is represented by $\delta$. A decline in $\delta$ implies a rise in the level of technological diffusion.

In stage two, the duopolists face the following inverse demand function:

$$
p=1-q_{1}-q_{2},
$$

where $p$ is the price and $q_{i}$ is the output of firm $i(i=1,2)$.

We solve the game backwards. We assume that

$$
\frac{1}{2}\left(1+c_{1 R}\right)>\delta c_{2 N} \text { and } \frac{1}{2}\left(1+\delta c_{2 R}\right)>c_{1 N} .
$$

These inequalities ensure positive profits.

There are four possible equilibria: $(R, R),(R, N),(N, R)$, and $(N, N)$. First, we consider that both firms 1 and 2 invest in $\mathrm{R} \& \mathrm{D}$. Firm 1 maximizes profit, $\pi_{1}$ with respect to $q_{1}$ :

$$
\pi_{1}=\left(1-q_{1}-q_{2}-c_{1 R}\right) q_{1}-F .
$$

The best-response function of firm 1 is then given by

$$
q_{1}=\frac{1-q_{2}-c_{1 R}}{2} .
$$

Firm 2 maximizes profit, $\pi_{2}$ with respect to $q_{2}$ :

$$
\pi_{2}=\left(1-q_{1}-q_{2}-\delta c_{2 R}\right) q_{2}-F .
$$

The best-response function of firm 2 is then given by

$$
q_{2}=\frac{1-q_{1}-\delta c_{2 R}}{2} .
$$

Equation (1) and Equation (2) imply

$$
q_{1}^{R R}=\frac{1-2 c_{1 R}+\delta c_{2 R}}{3} \text { and } q_{2}^{R R}=\frac{1-2 \delta c_{2 R}+c_{1 R}}{3},
$$

where we denote firm is output by $q_{i}^{j k} \quad(i=1,2, j, k=R, N)$ in which $j$ and $k$ represent the choice in $\mathrm{R} \& \mathrm{D}$ activity by firms 1 and 2 , respectively.

Thus, we obtain

$$
\pi_{1}^{R R}=\frac{\left(1-2 c_{1 R}+\delta c_{2 R}\right)^{2}}{9}-F \text { and } \pi_{2}^{R R}=\frac{\left(1-2 \delta c_{2 R}+c_{1 R}\right)^{2}}{9}-F,
$$

where we denote firm is profits by $\pi_{i}^{j k} \quad(i=1,2, j, k=R, N)$ in which $j$ and $k$ ${ }^{6}$ In the Appendix, we consider no technological diffusion when the minor firm invests in R \& D. 
represent the choice in R \& D activity by firms 1 and 2, respectively.

An increase in the level of technological diffusion, represented by a decline in $\delta$, increases the profit of firm 2, but decreases the profit of firm 1 .

Second, we consider that firm 1 but not firm 2 invests in R \& D. The profit of firm 1 is represented by

$$
\pi_{1}=\left(1-q_{1}-q_{2}-c_{1 R}\right) q_{1}-F .
$$

The best-response function is

$$
q_{1}=\frac{1-q_{2}-c_{1 R}}{2} .
$$

The profit of firm 2 is represented by

$$
\pi_{2}=\left(1-q_{1}-q_{2}-\delta c_{2 N}\right) q_{2}
$$

The best-response function is

$$
q_{2}=\frac{1-q_{1}-\delta c_{2 N}}{2} .
$$

Equation (3) and Equation (4) imply

$$
q_{1}^{R N}=\frac{1-2 c_{1 R}+\delta c_{2 N}}{3} \text { and } q_{2}^{R N}=\frac{1-2 \delta c_{2 N}+c_{1 R}}{3} .
$$

Thus, we obtain

$$
\pi_{1}^{R N}=\frac{\left(1-2 c_{1 R}+\delta c_{2 N}\right)^{2}}{9}-F \text { and } \pi_{2}^{R N}=\frac{\left(1-2 \delta c_{2 N}+c_{1 R}\right)^{2}}{9} .
$$

An increase in the level of technological diffusion increases the profit of firm 2 but decreases the profit of firm 1 .

Third, we consider that firm 2 but not firm 1 invests in R \& D. Firm 2 then cannot obtain any benefit from the spillover of $\mathrm{R} \& \mathrm{D}$ by firm 1 because firm 1 does not undertake $\mathrm{R} \& \mathrm{D}$ activity. The profit of firm 1 is represented by

$$
\pi_{1}=\left(1-q_{1}-q_{2}-c_{1 N}\right) q_{1} .
$$

The best-response function is

$$
q_{1}=\frac{1-q_{2}-c_{1 N}}{2} .
$$

The profit of firm 2 is represented by

$$
\pi_{2}=\left(1-q_{1}-q_{2}-c_{2}\right) q_{2}-F .
$$

The best-response function is

$$
q_{2}=\frac{1-q_{1}-c_{2 R}}{2} .
$$

Equation (5) and Equation (6) imply

$$
q_{1}^{N R}=\frac{1-2 c_{1 N}+c_{2 R}}{3} \text { and } q_{2}^{N R}=\frac{1-2 c_{2 R}+c_{1 N}}{3} .
$$

Thus, we obtain 


$$
\pi_{1}^{N R}=\frac{\left(1-2 c_{1 N}+c_{2 R}\right)^{2}}{9} \text { and } \pi_{2}^{N R}=\frac{\left(1-2 c_{2 R}+c_{1 N}\right)^{2}}{9}-F .
$$

Finally, we consider that neither firm 1 nor firm 2 invests in R \& D. The profit of firm 1 is represented by

$$
\pi_{1}=\left(1-q_{1}-q_{2}-c_{1 N}\right) q_{1} .
$$

The best-response function is

$$
q_{1}=\frac{1-q_{2}-c_{1 N}}{2} .
$$

The profit of firm 2 is represented by

$$
\pi_{2}=\left(1-q_{1}-q_{2}-c_{2 N}\right) q_{2} .
$$

The best-response function is

$$
q_{2}=\frac{1-q_{1}-c_{2 N}}{2} .
$$

Equation (7) and Equation (8) imply

$$
q_{1}^{N N}=\frac{1-2 c_{1 N}+c_{2 N}}{3} \text { and } q_{2}^{N N}=\frac{1-2 c_{2 N}+c_{1 N}}{3} .
$$

Thus, we obtain

$$
\pi_{1}^{N N}=\frac{\left(1-2 c_{1 N}+c_{2 N}\right)^{2}}{9} \text { and } \pi_{2}^{N N}=\frac{\left(1-2 c_{2 N}+c_{1 N}\right)^{2}}{9} .
$$

We now examine the boundary conditions for R \& D activity. We first examine the boundary conditions for firm 1 . The threshold of $\mathrm{R} \& \mathrm{D}$ cost between $R N$ and $N N$ for firm 1 is represented as follows:

$$
F=\frac{\left(1-2 c_{1 R}+\delta c_{2 N}\right)^{2}}{9}-\frac{\left(1-2 c_{1 N}+c_{2 N}\right)^{2}}{9} \equiv F_{1 N}(\delta) .
$$

when the level of technological diffusion is high in the case of $R N$, it is difficult for firm 1 to invest in $\mathrm{R} \& \mathrm{D}$ because $\frac{\partial F_{1 N}(\delta)}{\partial \delta}>0$. Because firm 2 puts pressure on firm 1 when there is a high level of technological diffusion, the profit of firm 1 decreases, and firm 1 thus loses any incentive for $\mathrm{R} \& \mathrm{D}$ activity.

The threshold of $\mathrm{R} \& \mathrm{D}$ cost between $R R$ and $N R$ for firm 1 is represented as

$$
F=\frac{\left(1-2 c_{1 R}+\delta c_{2 R}\right)^{2}}{9}-\frac{\left(1-2 c_{1 N}+c_{2 R}\right)^{2}}{9} \equiv F_{1 R}(\delta) .
$$

when the level of technological diffusion is high in the case of $R R$, it is difficult for firm 1 to invest in $\mathrm{R} \& \mathrm{D}$ because $\frac{\partial F_{1 R}(\delta)}{\partial \delta}>0$. When firm 2 puts pressure on firm 1 because of a high level of technological diffusion, firm 1 loses any incentive for $\mathrm{R} \& \mathrm{D}$ activity.

We next examine the boundary conditions for firm 2. The threshold of $\mathrm{R} \& \mathrm{D}$ cost between $N R$ and $N N$ for firm 2 is represented as 


$$
F=\frac{\left(1-2 c_{2 R}+c_{1 N}\right)^{2}}{9}-\frac{\left(1-2 c_{2 N}+c_{1 N}\right)^{2}}{9} \equiv F_{2 N} .
$$

Here, the level of technological diffusion does not affect the boundary represented by $F_{2 N}$ because there is no R \& D by firm 1 .

The threshold of $\mathrm{R} \& \mathrm{D}$ cost between $R R$ and $R N$ for firm 2 is represented as

$$
F=\frac{\left(1-2 \delta c_{2 R}+c_{1 R}\right)^{2}}{9}-\frac{\left(1-2 \delta c_{2 N}+c_{1 R}\right)^{2}}{9} \equiv F_{2 R}(\delta) .
$$

when the level of technological diffusion is high in the case of $R R$, it is easy for firm 2 to invest in $\mathrm{R} \& \mathrm{D}$ because $\frac{\partial F_{2 R}(\delta)}{\partial \delta}<0$. Because the profit of firm 2 increases with an increase in the level of technological diffusion, it is less difficult for firm 2 to invest in $\mathrm{R} \& \mathrm{D}$. Note that we have $F_{2 j}<F_{1 j} \quad(j=R, N)$ because the production costs of firm 1 are lower than those of firm 2.

Social welfare is defined as $S W \equiv C S+\pi_{1}+\pi_{2}$, where $C S$ is the consumer surplus. The consumer surplus can be represented by

$$
C S^{R k}=\frac{1}{18}\left[2-\left(c_{1 R}+\delta c_{2 k}\right)\right]^{2} \text { and } C S^{N k}=\frac{1}{18}\left[2-\left(c_{1 N}+c_{2 k}\right)\right]^{2},
$$

where we denote the consumer surplus by $C S^{j k} \quad(j, k=R, N)$ in which $j$ and $k$ represent the choice in $\mathrm{R} \& \mathrm{D}$ activity by firms 1 and 2 , respectively.

When firm 1 invests in $\mathrm{R} \& \mathrm{D}$, the consumer surplus increases with an increase in the level of technological diffusion because of a decline in the production cost of firm 2.

\section{How Does Technological Diffusion Affect Welfare via R \& D Competition?}

\subsection{R \& D Competition with the Existence of Technological Diffusion}

In this subsection, we examine the equilibrium according to the $\mathrm{R} \& \mathrm{D}$ cost and technological diffusion level. We first examine the boundary condition for firm 1's R \& D. When $\pi_{1}^{N N}>\pi_{1}^{R N}$ holds, the major firm cannot undertake R \& D activity. This condition can be written as

$$
F>F_{1 N}(1)=\frac{\left(1-2 c_{1 R}+c_{2 N}\right)^{2}}{9}-\frac{\left(1-2 c_{1 N}+c_{2 N}\right)^{2}}{9} .
$$

However, it is possible for firm 1 to invest in $\mathrm{R} \& \mathrm{D}$ depending on the level of technological diffusion if the $\mathrm{R} \& \mathrm{D}$ cost is lower than $F_{1 N}(1)$ :

$$
F<F_{1 N}(1) \text {. }
$$

We next examine the boundary condition for firm 2's R \& D. If $F>F_{2 N}$ holds, the minor firm does not undertake $\mathrm{R} \& \mathrm{D}$ activity, regardless of the level of technological diffusion because $\pi_{2}^{N N}>\pi_{2}^{N R}$. However, it is possible for the minor firm to invest in $\mathrm{R} \& \mathrm{D}$ when the $\mathrm{R} \& \mathrm{D}$ cost is lower than $F_{2 N}$ :

$$
F<F_{2 N} \text {. }
$$


We identify three cases of R \& D competition according to the R \& D feasibility conditions for firms 1 and 2 represented by (14), (15), and (16). First, if (14) holds, neither firm 1 nor firm 2 undertakes R \& D activity.

Next, if (15) but not (16) holds, it is possible for firm 1 to undertake R \& D. Using (9), we obtain the following relationship between firm 1's profit and the $\mathrm{R}$ \& D cost:

$$
\pi_{1}^{R N} \underset{<}{>} \pi_{1}^{N N} \Leftrightarrow F_{1 N}(\delta) \underset{<}{\stackrel{>}{<}} F
$$

when $F_{1 N}(\delta)<F$ holds, neither firm 1 nor firm 2 invests in R \& D. However, when $F<F_{1 N}(\delta)$ holds, firm 1 but not firm 2 invests in $\mathrm{R} \& \mathrm{D}$.

Let us consider the threshold of $\delta$ with respect to $\pi_{1}^{N N}=\pi_{1}^{R N}$ :

$$
\delta_{a} \equiv F_{1 N}^{-1}(F)=\frac{\left[9 F+\left(1-2 c_{1 N}+c_{2 N}\right)\right]^{1 / 2}}{c_{2 N}}-\frac{1-2_{1 R}}{c_{2 N}},
$$

where $\frac{\partial \delta_{a}}{\partial F}>0$ holds.

Lemma 1: 1) Suppose that $F_{1 N}(1)<F$ holds. $(N, N)$ is the Nash equilibrium, regardless of $\delta$. 2) Suppose that $F_{2 N}<F<F_{1 N}(1)$ holds. If $\delta_{a}<\delta$ holds, $(R, N)$ is the Nash equilibrium. If $\delta_{a}>\delta$ holds, $(N, N)$ is the Nash equilibrium.

Proof. 1) When $F_{1 N}(1)<F$ holds, we obtain $\pi_{1}^{N N}>\pi_{1}^{R N}$ for any $\delta$ because $\frac{\partial \pi_{1}^{R N}}{\partial \delta}>0$. We also have $\pi_{2}^{N N}>\pi_{2}^{N R}$.

2) In the range that $F_{2 N}<F<F_{1 N}(1)$, we have $\pi_{1}^{R N}>\pi_{1}^{N N}$ for $\delta=1$ and $\pi_{2}^{N N}>\pi_{2}^{N R}$ for any $\delta$. If $\delta_{a}<\delta$ holds, we have $\pi_{1}^{R N}>\pi_{1}^{N N}$. However, if $\delta_{a}>\delta$ holds, we have $\pi_{1}^{R N}<\pi_{1}^{N N}$. ॥

From Lemma 1, we illustrate Figure 1. In that figure, the vertical and

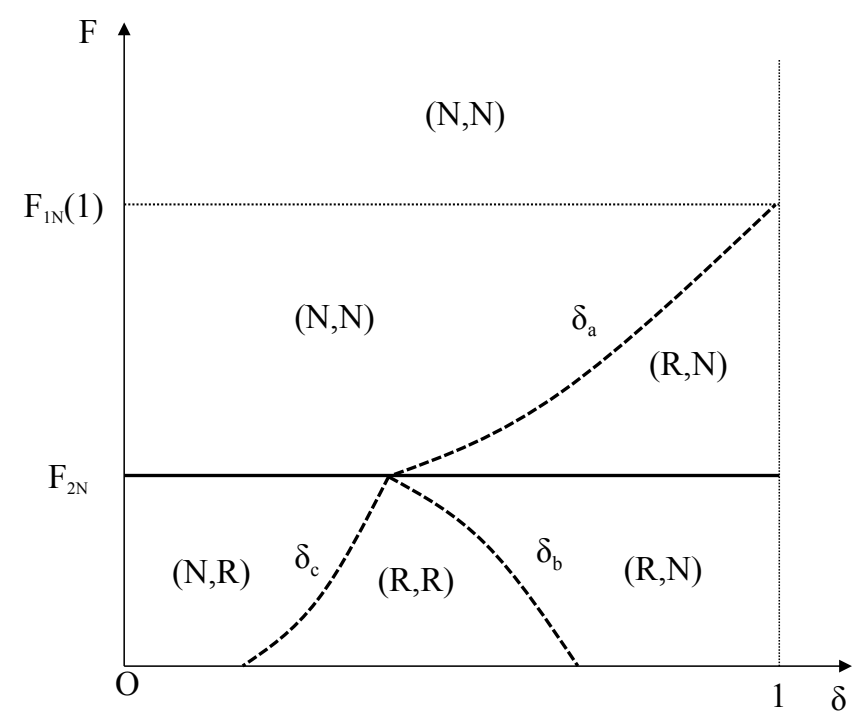

Figure 1. Nash equilibria according to the degree of technological diffusion and the R \& $\mathrm{D}$ cost. 
horizontal axes, respectively, represent the $\mathrm{R} \& \mathrm{D}$ cost and the degree of diffusion. We divide the available region into six regions, according to $\mathrm{R} \& \mathrm{D}$ investment by the major and minor firms. $N$ and $R$, respectively, represent no investment and a positive investment.

By use of Figure 1, we explain R \& D investment of the major and minor firms. It is impossible even for firm 1 to invest in $\mathrm{R} \& \mathrm{D}$ with a considerably high $\mathrm{R} \& \mathrm{D}$ cost. That is, $\mathrm{R} \& \mathrm{D}$ investment never occurs. However, if the $\mathrm{R} \& \mathrm{D}$ cost is not very high, firm 1 can commence $\mathrm{R} \& \mathrm{D}$ investment. A decline in $\delta$ decreases the boundary of $F$, that is, a lower $\mathrm{R} \& \mathrm{D}$ cost is required for the investment by firm 1 with a higher level of technological diffusion. Thus, if the level of technological diffusion is low, firm 1 invests in $\mathrm{R} \& \mathrm{D}$ and $(R, N)$ is the Nash equilibrium. There is only the free-riding effect. However, firm 1 ceases $\mathrm{R}$ \& D when firm 2 puts pressure on firm 1 owing to the high level of technological diffusion. Thus, if the level of technological diffusion is high, neither firm 1 nor firm 2 invests in $\mathrm{R} \& \mathrm{D}$ and $(N, N)$ is the Nash equilibrium. This implies no technological diffusion, that is, no free-riding effect.

Finally, if (16) holds, not only firm 1 but also firm 2 can undertake R \& D activity. Using (10), we have the following relationship between the profit of firm 1 and the $R \& D$ cost:

$$
\pi_{1}^{R R} \frac{\geq}{<} \pi_{1}^{N R} \Leftrightarrow F_{1 R}(\delta) \frac{\geq}{<} F .
$$

Furthermore, (12) implies the following relationship between the profit of firm 2 and the R \& D cost:

$$
\pi_{2}^{R R} \underset{<}{<} \pi_{2}^{R N} \Leftrightarrow F_{2 R}(\delta) \underset{<}{\geq} F .
$$

In the range that $F<F_{2 R}(\delta)$ and $F<F_{1 R}(\delta)$, both firm 1 and firm 2 invest in $\mathrm{R} \& \mathrm{D}$. Firm 1 but not firm 2 invests in $\mathrm{R} \& \mathrm{D}$ in the range where $F_{2 R}(\delta)<F<F_{1 R}(\delta)$. Firm 2 but not firm 1 invests in $\mathrm{R} \& \mathrm{D}$ in the range where $F_{1 R}(\delta)<F<F_{2 R}(\delta)$.

We consider the equality between $F_{1 R}(\delta)$ and $F_{2 R}(\delta)$ :

$$
F_{12 R} \equiv F_{1 R}(\hat{\delta})=F_{2 R}(\hat{\delta})<F_{2 N} \text {. }
$$

It is possible for both firms to invest in $\mathrm{R} \& \mathrm{D}$ when the $\mathrm{R} \& \mathrm{D}$ cost is lower than $F_{12 R}$.

Let us consider R \& D competition according to the level of technological diffusion. We can represent the threshold of $\delta$ with respect to $\pi_{2}^{R R}=\pi_{2}^{R N}$ as

$$
\delta_{b} \equiv F_{2 R}^{-1}(F)=\frac{1}{2}\left\{-\left(\frac{1+c_{1 R}}{c_{2 N}+c_{2 R}}\right)+\left[\left(\frac{1+c_{1 R}}{c_{2 N}+c_{2 R}}\right)^{2}+9 F\left(c_{2 N}-c_{2 R}\right)\right]^{1 / 2}\right\},
$$

where $\frac{\partial \delta_{b}}{\partial F}<0$ holds.

Further, the threshold of $\delta$ with respect to $\pi_{1}^{R R}=\pi_{1}^{N R}$ is represented as 


$$
\delta_{c} \equiv F_{1 R}^{-1}(F)=\frac{\left[9 F+\left(1-2 c_{1 N}+c_{2 R}\right)\right]^{1 / 2}}{c_{2 R}}-\frac{1-2 c_{1 R}}{c_{2 R}},
$$

where $\frac{\partial \delta_{c}}{\partial F}>0$ holds.

Lemma 2: Suppose that $F<F_{2 N}$ holds. If $\delta_{b}<\delta$ holds, $(R, N)$ is the Nash equilibrium. If $\delta_{c}<\delta<\delta_{b}$ holds, $(R, R)$ is the Nash equilibrium. If $\delta<\delta_{c}$ holds, $(N, R)$ is the Nash equilibrium.

Proof. In the range where $F<F_{2 N}$, we obtain $\pi_{1}^{R N}>\pi_{1}^{N N}$ and $\pi_{2}^{N R}>\pi_{2}^{N N}$. First, in the range that $\delta_{b}<\delta, \pi_{1}^{R N}>\pi_{1}^{N N}$ and $\pi_{2}^{R N}>\pi_{2}^{R R}$ hold. Next, in the range where $\delta_{c}<\delta<\delta_{b}, \pi_{1}^{R R}>\pi_{1}^{N R}$ and $\pi_{2}^{R R}>\pi_{2}^{R N}$ hold. Finally, in the range where $\delta<\delta_{c}, \pi_{1}^{N R}>\pi_{1}^{R R}$ and $\pi_{2}^{N R}>\pi_{2}^{N N}$ hold. \|

If the level of technological diffusion is low, as illustrated in Figure 1, firm 2 still does not invest in $\mathrm{R} \& \mathrm{D}$, even with a low $\mathrm{R} \& \mathrm{D}$ cost. Firm 1 can then invest in $\mathrm{R} \& \mathrm{D}$ with a low level of technological diffusion because of a large gap in production costs between the two firms. It is then beneficial for firm 2 to obtain the benefit from technological diffusion, given it has no $\mathrm{R} \& \mathrm{D}$ of its own, because the free-riding effect outweighs the taking-away effect. Thus, $(R, N)$ is the Nash equilibrium. An increase in the level of technological diffusion can promote R \& D by firm 2 . Because firm 2 can take market share away from firm 1, firm 2 undertakes the R \& D activity. Given a moderate level of technological diffusion, both firms invest in $\mathrm{R} \& \mathrm{D}$ with the coexistence of the free-riding and taking-away effects. That is, $(R, R)$ is the Nash equilibrium. However, firm 1 ceases $\mathrm{R} \& \mathrm{D}$ with a very high level of technological diffusion. If firm 1 invested in $\mathrm{R} \& \mathrm{D}$, the market share would be further reduced because of a small gap in production costs between the two firms and firm 1 would lose any incentive for $\mathrm{R} \& \mathrm{D}$. Firm 2 invests in R \& D cost with no technological diffusion because of the taking-away effect. Thus, $(N, R)$ is the Nash equilibrium.

From Lemmas 1 and 2, we have the following proposition.

Proposition 1: (Equilibrium that depends on the $R \& D$ cost and level of technological diffusion.) 1) If $F_{2 N}<F<F_{1 N}(1)$ holds, a low level of technological diffusion implies $R \& D$ by the major firm. 2) a) If $F_{12 R}<F<F_{2 N}$ holds, a low level of technological diffusion implies $R \& D$ by the major firm. $A$ high level of technological diffusion implies the abandonment of $R \& D$ by the major firm and the commencement of $R \& D$ by the minor firm. b) If $F<F_{12 R}$ holds, unless the level of technological diffusion is very high, the major firm invests in $R \& D$. The minor firm also invests in $R \& D$ with a high level of technological diffusion.

Finally, we examine the effect of production costs, not only on the thresholds for R \& D cost, but also on the levels of technological diffusion. By use of (11), (14), (17), (19), and (20), we obtain the following lemma.

Lemma 3: We have the following effects of production costs on $F_{1 N}(1)$ and $F_{2 N}$ : 


$$
\frac{\partial F_{1 N}(1)}{\partial c_{1 R}}<0, \frac{\partial F_{1 N}(1)}{\partial c_{1 N}}>0, \frac{\partial F_{1 N}(1)}{\partial c_{2 N}}>0, \frac{\partial F_{2 N}}{\partial c_{2 R}}<0, \frac{\partial F_{2 N}}{\partial c_{2 N}}>0, \frac{\partial F_{2 N}}{\partial c_{1 N}}>0 .
$$

Furthermore, we obtain the following effects of production costs on $\delta_{a}, \delta_{b}$, and $\delta_{c}$ :

$$
\begin{gathered}
\frac{\partial \delta_{a}}{\partial c_{1 R}}>0, \frac{\partial \delta_{a}}{\partial c_{1 N}}<0, \frac{\partial \delta_{a}}{\partial c_{2 N}} \frac{\geq}{<} 0, \frac{\partial \delta_{b}}{\partial c_{2 R}} \frac{\geq}{<} 0, \frac{\partial \delta_{b}}{\partial c_{2 N}}>0, \frac{\partial \delta_{b}}{\partial c_{1 R}}>0, \\
\frac{\partial \delta_{c}}{\partial c_{1 R}}>0, \frac{\partial \delta_{c}}{\partial c_{1 N}}<0, \frac{\partial \delta_{c}}{\partial c_{2 R}}<0 .
\end{gathered}
$$

Proof. From (17), we have

$$
\frac{\partial \delta_{a}}{\partial c_{2 N}} \geq 0 \Leftrightarrow-\frac{1}{2}\left[\frac{9 F}{c_{2 N}^{2}}+\left(\frac{1-2 c_{1 N}}{c_{2 N}}+1\right)^{2}\right]^{-1 / 2} \frac{9 F}{c_{2 N}^{3}}+\frac{1-2 c_{1 R}}{c_{2 N}^{2}} \frac{\geq}{<} 0 .
$$

From (19), we obtain

$$
\begin{aligned}
\frac{\partial \delta_{b}}{\partial c_{2 R}}<0 \Leftrightarrow & \frac{1+c_{1 R}}{\left(c_{2 N}+c_{2 R}\right)^{2}}+\frac{1}{2}\left[\left(\frac{1+c_{1 R}}{c_{2 N}+c_{2 R}}\right)^{2}+\frac{9 F}{c_{2 N}-c_{2 R}}\right]^{-1 / 2} \| \\
& \times\left[-2 \frac{1+c_{1 R}}{\left(c_{2 N}+c_{2 R}\right)^{3}}+\frac{9 F}{\left(c_{2 N}-c_{2 R}\right)^{2}}\right] \geq 0 .
\end{aligned}
$$

We have $\frac{\partial \delta_{a}}{\partial c_{2 N}}<0$ with a large $F$. When $\left(c_{2 N}-c_{2 R}\right)$ is large, we have $\frac{\partial \delta_{b}}{\partial c_{2 R}}<0$. Note that the high efficiency of firm is R \& D is implied by a large $c_{i N}$,

a small $c_{i R}$, and a small $F(i=1,2)$.

If the efficiency of the major firm's $\mathrm{R} \& \mathrm{D}$ is high, the equilibrium in which the major firm invests in $\mathrm{R} \& \mathrm{D}$ holds more easily. However, it would be more difficult for the major firm to invest in $\mathrm{R} \& \mathrm{D}$ when there is a high level of efficiency in the minor firm's production. This is because the efficient production of the minor firm decreases the profit of the major firm. Furthermore, the equilibrium in which the minor firm invests in R \& D holds more easily when there is a high level of efficiency in the minor firm's production. The efficient production of the major firm could then retard the commencement of $\mathrm{R} \& \mathrm{D}$ investment by the minor firm because it would be more beneficial for the minor firm to obtain instead the spillover effect of R \& D from the major firm.

From Lemma 3, we have the following proposition.

Proposition 2: (Effect of production costs on equilibrium.) When there is a high level of efficiency in the minor firm's production, it is more difficult for the major firm to invest in $R \& D$. When there is a high level of efficiency in the major firm's production, it is more difficult for the minor firm to invest in $R \&$ $D$. 


\subsection{Effect of Technological Diffusion on Welfare via R \& D Competition}

In this subsection, we examine the effect of technological diffusion on social welfare. We first consider the case in which (15) but not (16) holds, that is, where firm 1 but not firm 2 can undertake R \& D activity.

Lemma 4: Suppose that $F_{2 N}<F<F_{1 N}(1)$ and $\delta_{a}<\delta$ hold. We have:

$$
\frac{\partial \pi_{1}^{R N}}{\partial \delta}>0, \frac{\partial \pi_{2}^{R N}}{\partial \delta}<0, \frac{\partial C S^{R N}}{\partial \delta}<0
$$

We also have $\frac{\partial S W^{R N}}{\partial \delta}<0$ when $c_{2 N}$ is sufficiently low:

$$
\delta c_{2 N}<\frac{7 c_{1 R}+4}{11} .
$$

Proof. Social welfare in the equilibrium $(R, N)$ is represented as

$$
\begin{aligned}
S W^{R N} & =C S^{R N}+\pi_{1}^{R N}+\pi_{2}^{R N} \\
& =\frac{\left(2-c_{1 R}-\delta c_{2 N}\right)^{2}}{18}+\frac{\left(1-2 c_{1 R}+\delta c_{2 N}\right)^{2}}{9}-F+\frac{\left(1-2 \delta c_{2 N}+c_{1 R}\right)^{2}}{9} .
\end{aligned}
$$

Thus, under condition (20), $\frac{\partial S W^{R N}}{\partial \delta}<0$ holds. ॥

In equilibrium $(R, N)$, an increase in the level of technological diffusion increases the profit of firm 2 and consumer surplus, but decreases the profit of firm 1. Unless (21) holds, we have $\frac{\partial S W^{R N}}{\partial \delta}>0$. If the production cost of firm 2, represented by $c_{2 N}$, is high, catching up by the minor firm owing to technological diffusion can decrease social welfare because of the increasingly inefficient production of firm 2. This is the Lahiri-Ono effect.

In Figure 2, we illustrate two figures in which $F_{2 N}<F<F_{1 N}(1)$ : the upper one represents the profits of major and minor firms and the consumer surplus, while the lower one represents the social welfare. We have the threshold in the level of technological diffusion, $\delta_{a}$ between $(N, N)$ and $(R, N)$. When firm 1 ceases $\mathrm{R} \& \mathrm{D}$ with a high level of technological diffusion, firm 2 cannot obtain benefit from the spillover resulting from $\mathrm{R} \& \mathrm{D}$ by firm 1 . Because the production costs of both firms 1 and 2 increase owing to the abandonment of $\mathrm{R}$ \& D by firm 1, consumer surplus declines.

Proposition 3: (Effect of technological diffusion on social welfare when the $R$ $\& D$ cost is high.) Suppose $F_{2 N}<F<F_{1 N}(1)$ holds. In the range that $\delta_{a}<\delta$, under condition (21), an increase in the level of technological diffusion can increase social welfare. However, social welfare declines at $\delta=\delta_{a}$ because of the abandonment of $R \& D$ by the major firm.

Proof. We have the following relationships at $\delta=\delta_{a}$ :

$$
C S^{R N}>C S^{N N}, \pi_{1}^{R N}=\pi_{1}^{N N} \text { and } \pi_{2}^{R N}>\pi_{2}^{N N} .
$$

Thus, $S W^{N N}<S W^{R N}$ holds at $\delta=\delta_{a}$. ॥ 

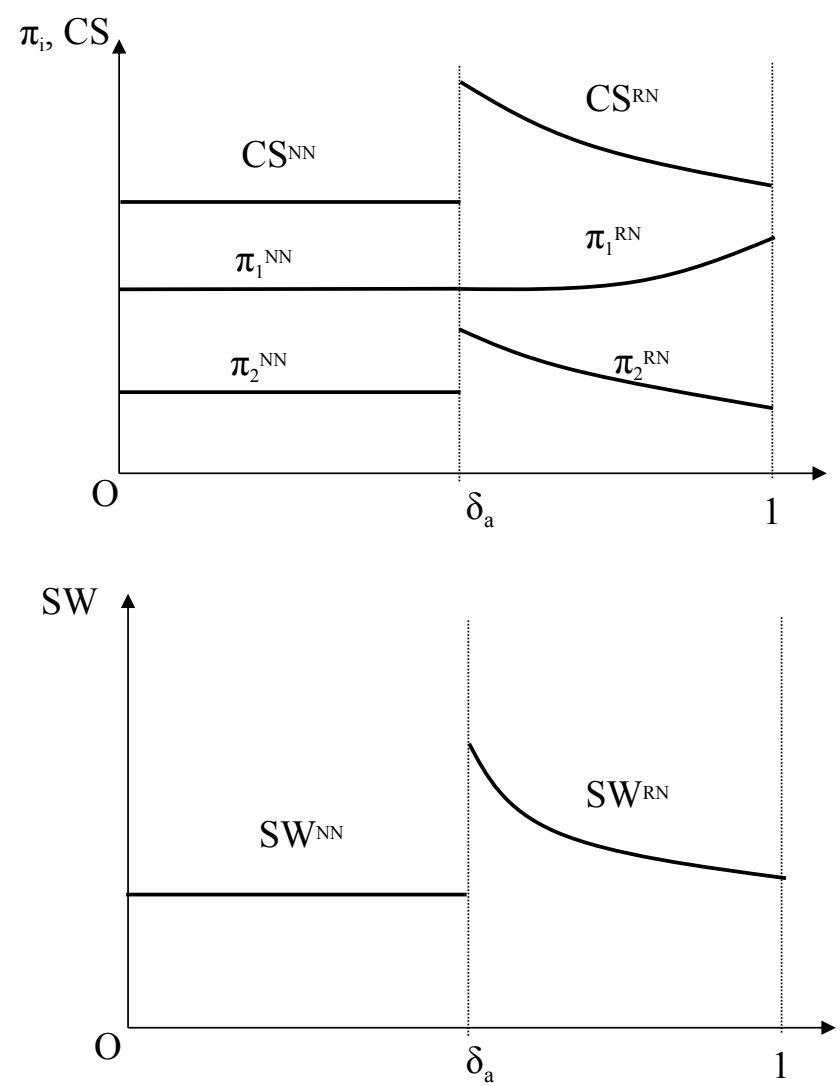

Figure 2. Profits of firms, consumer surplus, and social welfare in which F2N $<$ F $<$ F1N (1) holds.

We next consider the case in which (16) holds, that is, where both firms 1 and 2 can undertake R \& D activity.

Lemma 5: Suppose that $F<F_{2 N}$. If $\delta_{b}<\delta$ holds, we have:

$$
\frac{\partial \pi_{1}^{R N}}{\partial \delta}>0, \frac{\partial \pi_{2}^{R N}}{\partial \delta}<0, \frac{\partial C S^{R N}}{\partial \delta}<0
$$

Assuming that (21) holds, we have $\frac{\partial S W^{R N}}{\partial \delta}<0$. If $\delta_{c}<\delta<\delta_{b}$ holds, we have:

$$
\frac{\partial \pi_{1}^{R R}}{\partial \delta}>0, \frac{\partial \pi_{2}^{R R}}{\partial \delta}<0, \frac{\partial C S^{R R}}{\partial \delta}<0 .
$$

We also have $\frac{\partial S W^{R R}}{\partial \delta}<0$ when $c_{2 R}$ is sufficiently low:

$$
\delta c_{2 R}<\frac{7 c_{1 R}+4}{11} .
$$

Proof. Social welfare in the equilibrium $(R, R)$ is represented as

$$
\begin{aligned}
S W^{R R} & =C S^{R R}+\pi_{1}^{R R}+\pi_{2}^{R R} \\
& =\frac{\left(2-c_{1 R}-\delta c_{2 R}\right)^{2}}{18}+\frac{\left(1-2 c_{1 R}+\delta c_{2 R}\right)^{2}}{9}-F+\frac{\left(1-2 \delta c_{2 R}+c_{1 R}\right)^{2}}{9}-F .
\end{aligned}
$$


Thus, under condition (21), $\frac{\partial S W^{R R}}{\partial \delta}<0$ holds. \|

In equilibrium $(R, R)$, an increase in the level of technological diffusion increases the profit of firm 2 and consumer surplus, but decreases the profit of firm 1. Unless (22) holds, we have $\frac{\partial S W^{R R}}{\partial \delta}>0$. If the production cost of firm 2, represented by $c_{2 R}$, is high, catching up by the minor firm owing to technological diffusion can decrease social welfare.

Figure 3 illustrates the profits of firms 1 and 2, the consumer surplus, and social welfare in which $F<F_{2 N}$ holds. If the level of technological diffusion is high, the minor firm can commence $\mathrm{R} \& \mathrm{D}$ investment. This investment decreases the profit of the major firm but increases the consumer surplus. Thus, social welfare depends on the changes in consumer surplus and the profits of the major and minor firms. If the increase in consumer surplus and the profit of the minor firm is large, we can obtain a high level of social welfare. As long as the major firm invests in $\mathrm{R} \& \mathrm{D}$, we can obtain a high level of social welfare because of $\mathrm{R} \& \mathrm{D}$ by both firms. However, a very high level of technological diffusion implies the abandonment of $\mathrm{R} \& \mathrm{D}$ by the major firm. Consumer surplus then declines because the production costs of the major firm and the minor firm
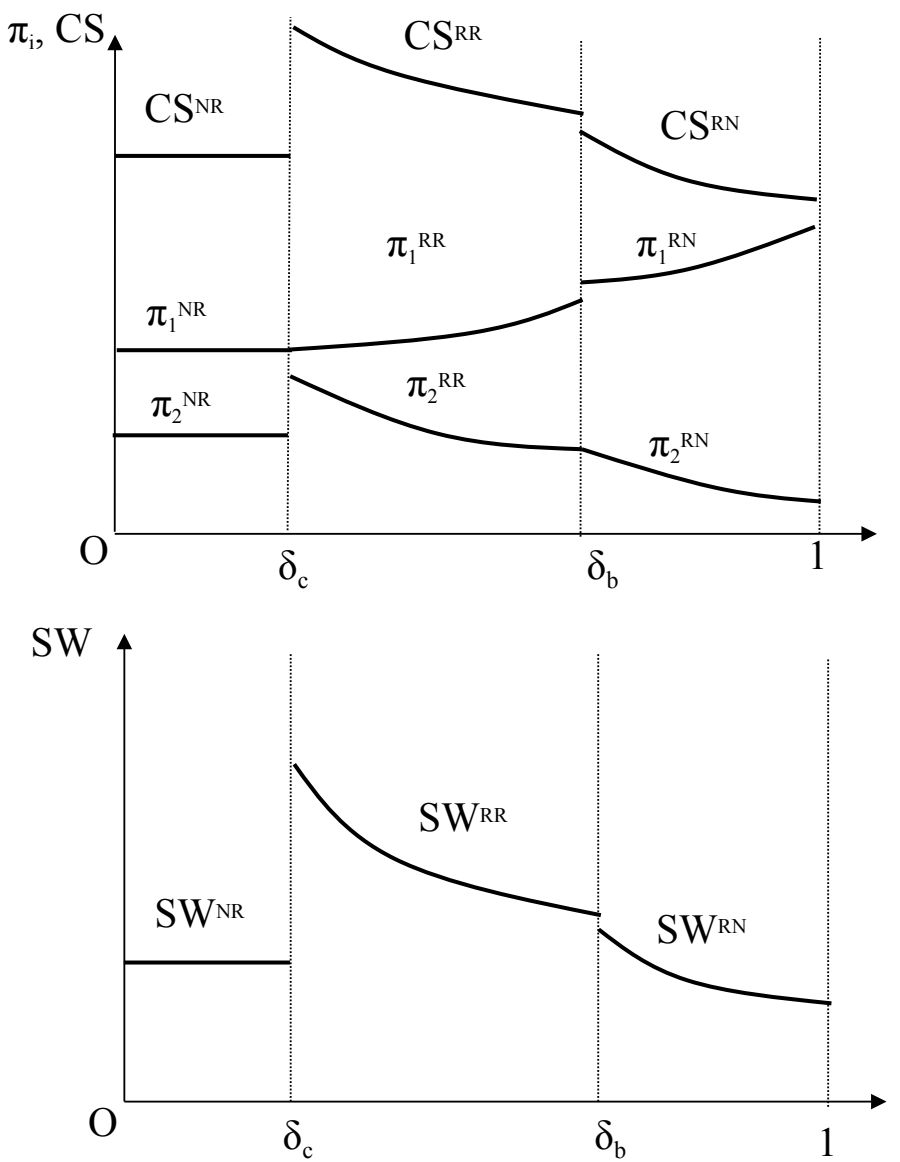

Figure 3. Profits of firms, consumer surplus, and social welfare in which $\mathrm{F}<\mathrm{F} 2 \mathrm{~N}$ holds. 
increase owing to the abandonment of R \& D by the major firm. When the profit of the minor firm declines, social welfare will necessarily decline. The decline can be large even with $\mathrm{R} \& \mathrm{D}$ by the minor firm because the production of the minor firm is less efficient.

Proposition 4: (Effect of technological diffusion on social welfare when the $R$ $\& D$ cost is low.) Suppose that $F<F_{2 N}$ holds. In the range where $\delta_{b}<\delta$, under condition (21), an increase in the level of technological diffusion can increase social welfare. If the increase in consumer surplus outweighs the decline in the major firm's profit at $\delta=\delta_{b}$, social welfare would increase because of the commencement of $R \& D$ by the minor firm. In the range where $\delta_{c}<\delta<\delta_{b}$, under condition (22), an increase in the level of technological diffusion can also increase social welfare. However, if the minor firm's profit declines at $\delta=\delta_{c}$, social welfare will also decline owing to the abandonment of $R \& D$ by the major firm.

Proof. We have $\pi_{1}^{R R}<\pi_{1}^{R N}, \pi_{2}^{R R}=\pi_{2}^{R N}$, and $C S^{R R}>C S^{R N}$ at $\delta=\delta_{b}$. Thus, if $C S^{R R}-C S^{R N}>\pi_{1}^{R N}-\pi_{1}^{R R}$ holds, $S W^{R R}>S W^{R N}$ holds at $\delta=\delta_{b}$.

Further, at $\delta=\delta_{c}$, we have $\pi_{1}^{N R}=\pi_{1}^{R R}, \pi_{2}^{N R} \geq \pi_{2}^{R R}$, and $C S^{N R}<C S^{R R}$. Thus, if $\pi_{2}^{N R}<\pi_{2}^{R R}$ holds, $S W^{N R}<S W^{R R}$ holds at $\delta=\delta_{c}$. ॥

\section{Concluding Remarks}

This study examined how technological diffusion from a major firm to a minor firm affects social welfare via $R \& D$ competition. Depending on the R \& D cost and production costs of firms, the potential existence of technological diffusion can disrupt R \& D by the major firm. If the R \& D cost is low, the decision of $\mathrm{R}$ $\& \mathrm{D}$ by the minor firm depends on the free-riding and taking-away effects. Given a moderate level of technological diffusion, both firms can invest in R \& D with the coexistence of the free-riding and taking-away effects and welfare will be very high.

The minor firm can obtain the benefit of technological diffusion as long as the major firm does not cease R \& D activity. Consumers also can benefit from technological diffusion because it decreases the production cost of the minor firm. Thus, the government should not increase much the level of technological diffusion to make the major firm continue R \& D. Given a low R \& D cost, a high level of social welfare would be possible with neither an excessively high nor an excessively low level of technological diffusion. Stronger regulation would be required with higher $\mathrm{R} \& \mathrm{D}$ cost and a smaller gap in production costs between the two firms, not to cease R \& D activity by the major firm.

In our model, we did not examine leapfrogging by a minor firm. For example, in China, domestic firms in the home electronics industry have defeated their multinational counterparts. In the future, we will explore how a minor firm can overtake a major firm by R \& D activity.

\section{Conflicts of Interest}

The authors declare no conflicts of interest regarding the publication of this paper. 


\section{References}

[1] Bernstein, J.I. and Pierre, M. (1998) International R \& D Spillovers between U.S. and Japanese R \& D Intensive Sectors. Journal of International Economics, 44, 315-338. https://doi.org/10.1016/S0022-1996(97)00026-3

[2] Keller, W. (2004) International Technology Diffusion. Journal of Economic Literature, 92, 752-782. https://doi.org/10.1257/0022051042177685

[3] Braguinsky, S. (2015) Knowledge Diffusion and Industry Growth: The Case of Japan's Early Cotton Spinning Industry. Industrial and Corporate Change, 24, 769-790. https://doi.org/10.1093/icc/dtv029

[4] Xie, W. and Wu, G. (2003) Differences between Learning Processes in Small Tigers and Large Dragons: Learning Processes of Two Colour TV (CTV) Firms within China. Research Policy, 32, 1463-1479. https://doi.org/10.1016/S0048-7333(02)00140-3

[5] Huang, S. and Qiao, W. (2005) The Development of China's Electronics Industry: Causes and Constraints. China and World Economy, 13, 107-122.

[6] Chen, C., Sheng, Y. and Findlay, C. (2013) Export Spillovers and FDI on China's Domestic Firms. Review of International Economics, 21, 841-856. https://doi.org/10.1111/roie.12074

[7] Ferrett, B. (2012) R \& D Competition in an Asymmetric Cournot Duopoly: The Welfare Effects of Catch-Up by the Lagged Firm. mimeo.

[8] Lahiri, S. and Ono, Y. (1988) Helping Minor Firms Reduces Welfare. Economic Journal, 98, 1199-1202. https://doi.org/10.2307/2233727

[9] Katz, M. and Shapiro, C. (1985) On the Licensing of Innovation. Rand Journal of Economics, 16, 504-520.

[10] Klemperer, P. (1990) How Broad Should the Scope of Patent Protection Be? Rand Journal of Economics, 21, 223-230.

[11] Sakakibara, M. and Branstetter, L. (2001) Do Stronger Patents Induce More Innovation? Evidence from the 1998 Japanese Patent Law Reforms. Rand Journal of Economics, 32, 77-100.

[12] Futagami, K. and Iwaisako, T. (2007) Dynamic Analysis of Patent Policy in an Endogenous Growth Model. Journal of Economic Theory, 132, 306-334.

https://doi.org/10.1016/j.jet.2005.07.009 


\section{Appendix}

When the minor firm catches up with the major firm, it may be difficult for the minor firm to enjoy technological diffusion from the major firm's R \& D. In this appendix, we consider no technological diffusion when the minor firm invests in $\mathrm{R} \& \mathrm{D}$.

When firm 2 invests in $\mathrm{R} \& \mathrm{D}$, because of no technological diffusion, the profit of firm 1 is represented as

$$
\pi_{1}^{R R}=\frac{\left(1-2 c_{1 R}+c_{2 R}\right)^{2}}{9}-F .
$$

Because firm 2 cannot have technological diffusion with its own $\mathrm{R} \& \mathrm{D}$, the profit of firm 2 is represented as

$$
\pi_{2}^{R R}=\frac{\left(1-2 c_{2 R}+c_{1 R}\right)^{2}}{9}-F .
$$

Equation (A1) implies that the threshold of the R \& D cost for firm 1 does not depend on the level of technological diffusion when firm 2 invests in R \& D:

$$
\pi_{1}^{R R} \frac{\geq}{<} \pi_{1}^{N R} \Leftrightarrow F_{1 R} \frac{\geq}{<} F
$$

where

$$
F_{1 R} \equiv \frac{\left(1-2 c_{1 R}+c_{2 R}\right)^{2}}{9}-\frac{\left(1-2 c_{1 N}+c_{2 R}\right)^{2}}{9} .
$$

Note that $F_{2 N}<F_{1 R}<F_{1 N}(1)$.

Using (A2), the threshold of the R \& D cost for firm 2 can be represented as follows:

$$
\pi_{2}^{R R} \frac{\geq}{<} \pi_{2}^{R N} \Leftrightarrow F_{2 R}(\delta) \underset{<}{\geq} F,
$$

where

$$
F_{2 R}(\delta) \equiv \frac{\left(1-2 c_{2 R}+c_{1 R}\right)^{2}}{9}-\frac{\left(1-2 \delta c_{2 N}+c_{1 R}\right)^{2}}{9} .
$$

Equation (A4) implies the threshold of $\delta$ with respect to $\pi_{2}^{R R}=\pi_{2}^{R N}$ :

$$
\delta_{b}=F_{2 R}^{-1}(F)=\frac{1}{2 c_{2 N}}\left\{\left(1+c_{1 R}\right)-\left[\left(1-2 c_{2 R}+c_{1 R}\right)^{2}-9 F\right]^{1 / 2}\right\} .
$$

We have $\frac{\partial F_{2 R}(\delta)}{\partial \delta}>0$ and $\frac{\partial \delta_{b}}{\partial F}>0$. That is, a low threshold of $\mathrm{R} \& \mathrm{D}$ cost is implied by a high level of technological diffusion. If firm 2 does not invest in $\mathrm{R}$ \& D, firm 2 can enjoy technological diffusion as long as firm 1 invests in $\mathrm{R} \& \mathrm{D}$. It is more difficult for firm 2 to undertake $\mathrm{R} \& \mathrm{D}$ activity because of the free-riding effect. Thus, the existence of technological diffusion disturbs $\mathrm{R} \& \mathrm{D}$ by the minor firm.

Figure A1 illustrates the equilibrium according to the R \& D cost and technological diffusion level. Compared with Figure $1,(R, R)$ can hold when 


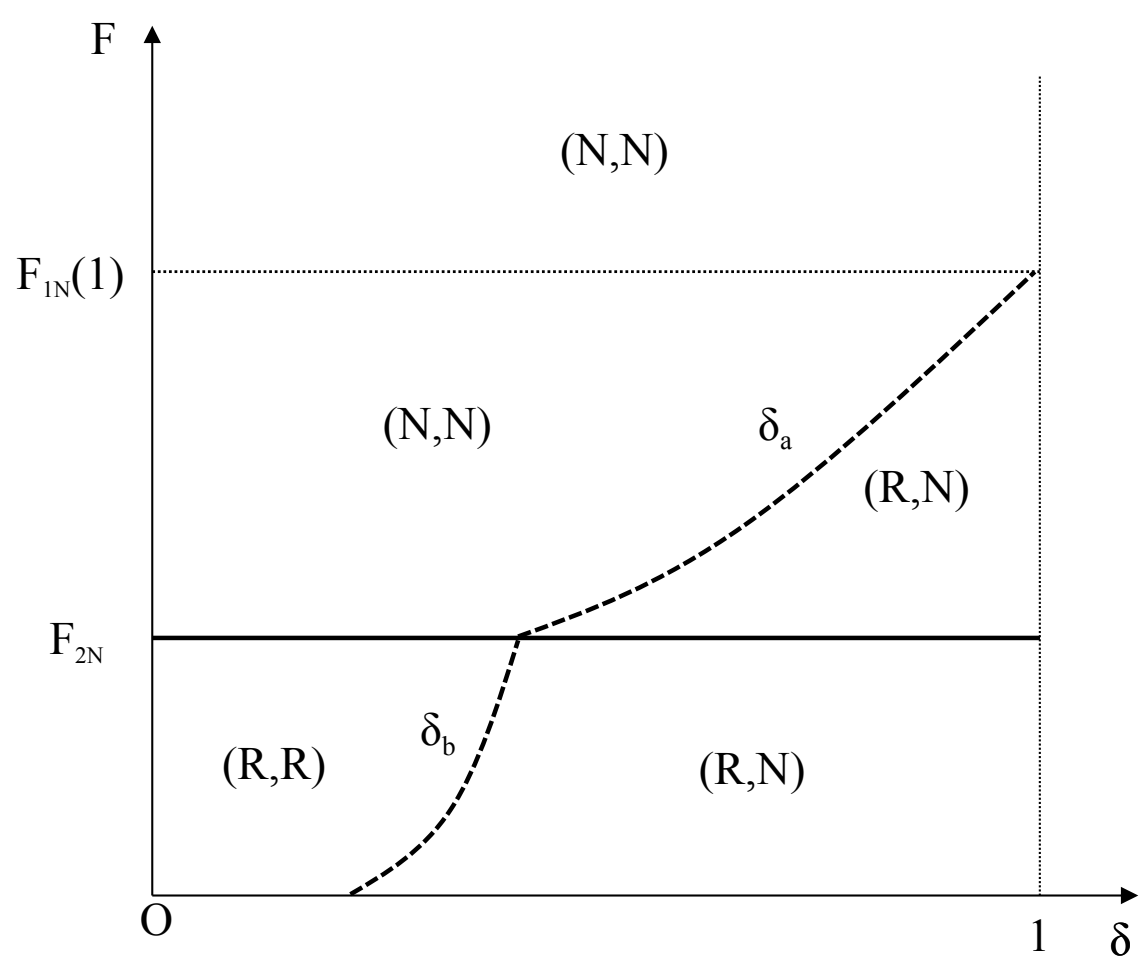

Figure A1. Nash equilibrium when the minor firm's R \& D implies no technological diffusion from the major firm.

the R \& D cost is low and the level of technological diffusion is high. Because firm 2 cannot enjoy technological diffusion with its own $\mathrm{R} \& \mathrm{D}$, firm 2 retards the commencement of R \& D investment. The delay in the commencement of $\mathrm{R}$ $\& \mathrm{D}$ by the minor firm implies a negative effect on the consumer surplus. In the equilibrium $(R, R)$, the level of technological diffusion no longer affects firm 1 's profit. That is, only the taking-away effect exists. Firm 1 does not cease R \& D because of no technological diffusion and the equilibrium $(N, R)$ never holds. Consequently, consumers benefit from R \& D by both firms. 